\title{
Going Begging: Casino Culture and its Contrasts as Revealed in the New Macao Poetry
}

\author{
By Christopher (Kit) Kelen
}

\begin{abstract}
Among the key themes of contemporary Macao poetry, chance and luck loom large, along with their figuration in Macao life through sites such as casinos and temples, through personae such as those of the gambler, the beggar, the prostitute. Macao as dot-on-the-map is likewise conceived as a site for all kinds of portal semiotics, as paradigm for cultural crossing and cultural shift. Macao may be regarded as a work enduring (in Brechtian terms) because it is unfinished. While this is a formula that could be notionally applied to any city, this view seems particularly apt given both the extraordinary pace of change in post-handover Macao (i.e. since 1999), and the present bubble-bursting effect of the 2008 "financial tsunami”.

Relating Augé's conception of “non-places” to Eco's notion of open (as opposed to closed) text, this paper observes that consciousness of place in contemporary Macao poetry appears to be dominated by two kinds of space, glossed here as "Macao space" and "anywhere space”. Macao space is uniquely of an historical moment and place, something culturally positioned; in anywhere space (e.g. inside of a casino or an airport) subjects are hailed by consumption-oriented reifications of putative universal value. The contemporary Macao poetry typically values Macao space and sees it as under threat from the "non-negotiable" space of culture that could be anywhere.

Interested in the paradoxes, ironies and hypocrisies inherent in the present-day culture, politics and international position of Macao, the new Macao poetry reveals a place-based poetics deeply concerned with Macao identity, its evolution and potentials.
\end{abstract}

Keywords: Macao, poetry, place, space 


\section{Going Begging - Casino Culture and its Contrasts as Revealed in the New Macao Poetry}

Macao - dot on the map and longstanding east/west portal - serves as a poetic symbol. Macao, the old city in south China, is a well inhabited territory - and so a place of poetic witness. Tension between conceptions of place implied by the Platonic as opposed to the empirical city is evidenced in contemporary Macao poetry. It is with such tensions and with the symbolic qualities of the imagined place this paper is concerned. This essay deals with a number of key themes in Macao poetry today; among these chance and luck loom large, along with their figuration in Macao life through sites such as casinos and temples, through personae such as those of the gambler, the beggar, the prostitute. The method of the investigation is to bring pertinent theory (especially concerning the postmodern city and cinematic space) into play in the consideration of contemporary Macao poetry (written in English or translated from Chinese or Portuguese). The reason for focusing on poetry in this manner is that this medium of witness has been uniquely suited to the fashioning of a subtle and on-going critique of the way things are and the powers that be in Macao.

$* * *$

The "mountains" around Macao - the high hills seen from almost everywhere in Macao - are all in fact across the border, on what people in Macao call the Mainland (or $d a l u$ - the big land or nei $d i$ - the ground inside). These mountains do not belong to the territory; they are not controlled by Macao's government. To get to them one must cross the border into China proper. These ranges are like the mountain backdrop of a Japanese garden - a convenient theft for aesthetic purposes. Macao's mountains (some now windmill clad) are something borrowed by virtue of a vantage point. And yet surely a view is part of a place? Those high hills are a reminder that - for better and worse (richer and poorer, etc.) - Macao is a part of China.

Those mountains are only one of a number of local spatial illusions. Perhaps illusions of size are necessary to a place on Macao's scale? The illusion of a sea is potent in this Pearl River port. And there is the illusion that Macao is an island, as demonstrated in Wong Man Fai's 2005 poem, “I'm on an island”:

I'm on this island

I use my eyes to write about its stories

of course originally I planned to read it with my tongue

but now the story is not yet finished

because I can almost see my breath

when passing the alleys

one after another, the lost fear restrains

the songs in my throat 
leaving my eyeballs prosthetic

and the net filled with blood

I'm constantly questioning

the island

$\mathrm{AV} \& \mathrm{KK}^{1}(227)$

Needless to say, Macao is not an island, or not simply, literally, an island. In geographic terms, it's a peninsula and two islands. It's part of China (PRC). It was possibly a Portuguese possession for four hundred and fifty years, though not really a colony - historians generally agree to call it an enclave. ${ }^{2}$ And though this tiny territory was arguably never in law properly alienated from China - though it never properly belonged to Europe - still a Hong Kong handover style of treaty was signed between Beijing and Lisbon in 1987. As a result the Portuguese and the citizens of Macao found themselves with virtually the same benefits posthandover that London had negotiated for its crown colony across the delta. Those benefits principally include fifty years of guaranteed civic autonomy and protection for Portuguese language and Portuguese law. At the time of writing, ten years after the institution of the one country two-systems policy, one hardly hears the phrase mentioned. That might generally indicate that it's working.

Why then call Macao an island? It's a popular misconception. And certainly if one looks at the old maps, it is a very narrow isthmus that joined the peninsula of Macao to the rest of China. In the more distant past, before a sandbar silted into an isthmus, what is now peninsula Macao was in fact an island. Today Macao is nearly three times in area what it was at the beginning of the twentieth century; and land reclamation started hundreds of years before that. Nor is it hard to see what drove the reclamation. Despite its rapid expansion in area Macao remains the most crowded territory on earth, with a population density four times that of Hong Kong. It's true that parts of Hong Kong - places like Mongkok and Sham Shui Po and Kowloon - are the most crowded square kilometres on the planet; Hong Kong's overall population density is greatly diluted by the fact that more than $40 \%$ of the land area is country park (and in fact less than $20 \%$ of the total land area is fully urbanised). Macao is almost entirely lacking in "country" as such. Because of its small size, Macao presents as the paradigm case of place as the "point on the map".

In Macao we witness the miracle of city space made more through the inexorable reclamation of the land from the shallow silty river - the city's future (and the future of its capital) is not limited to the territory it seems on the ground to be. Returning to the map, we can see in Macao something akin to the figure suggested by Borges and Baudrillard - of the map exceeding the territory it might have been meant to describe. The map of what Macao will be - that imagination of Macao, the aerial view of empty space reclaimed (as seen from the old Macao-Taipa Bridge) - today tangibly exceeds the territory through which the population can freely move. It is because of the land reclaimed being earmarked for casino- 
capitalist development, we can speak of the territory added as being something other than Macao-space.

The illusions on which Macao depends are not merely confined to someone else's mountains and a river pretending to be a sea. Portugal too is part of Macao. It's all of Portugal most Chinese people ever see and yet the impression - via food, via television, shop signs, announcements in theatres - can be very convincing. This is Portugal run at a distance by a skeleton staff.

In what sense then should we consider Macao to be an island? Note that other poets have employed the same conceit, for instance in Chan Sok Wa "the moment of waking" we have reference to "the island kingdom" (362). Is the miniature place (the place of miniatures) able to be set aside? Is Macao metaphorically an island in the sense, John Donne informs us, that "no man is"? Is Macao exceptional, unique? Do the rules of elsewhere not apply in Macao? Perhaps it's not so much the answers but the questions that are important. To return to Wong Man Fai's poem, I think the key is in the lines, "I'm constantly questioning/ the island.” This kind of questioning is then of a fundamental kind - it goes to the nature of existence and to the senses of identity that are possible in a place. With what measure of reality should a place be credited? The present day world - of postmodernity, of late capitalism - is one full of illusions of scale and pace. Perhaps these are more potent or apparent when they occur in the place which is a dot on the map.

Gambling, for instance, is a most potent of illusions - the idea that the punter can win is of course contradicted by the fact that s/he is entering a palace and someone's money had to pay for it. The Wong Man Fai poem, the end of which is presented above, begins:

I'm on an island tall buildings erect

fences surround the prison

inviting glances

charming nights one after another

staggering steps on the streets

we have a pit here

placing the bets with shabby souls

chaos, confusion - this compensation

like faces patched out of...

So the island is also a prison - like Hamlet's Denmark - one in which gambling is the compensation for shabby souls. In the Wong poem the charm - as advertised - and the drunken stagger of the reveller provide an apt image of ambivalence. In the chaos and confusion, where identity is something patched together, we begin to recognise "the island" as floating signifier. Is it the case that Macao can be all things to all? Perhaps this is the beauty of the place with no extent. 


\section{Uniqueness - or Gambling with Macao Characteristics}

Macao as metaphor is bi-directional, and reversible. In other words, disclosing the metaphor means that there are two distinct questions to be answered: What does Macao represent?/How is Macao represented? There are a number of planes on which these questions and answers can be tilted, confused. For instance, the question of representation has a political as well as a semiotic dimension. And so we can ask, for instance: Who has the right to represent Macao? And to whom? Nor, rhetorically, is it merely metaphor that is at stake here. We need to interrogate the various associations Macao brings to mind for the resident, for the tourist, for the prospective visitor. Here, marketing meets governance, corporate and otherwise. And there is the question of part/whole relations, the obvious shift in that instance being from participation in a European world empire to being a part of China again to being a part of a world capitalist experiment in the so-called pleasure of gambling. These foregoing are in outline some of the dimensions of connotation carried by the use of the word "Macao".

Macao's newfound prosperity is based on gambling and "the gaming industry" (as it euphemistically declares itself) is a focus and locus for many of the key contradictions. Prior to the financial tsunami of the second half of 2008, it had been apparent to all in Macao that the rich were getting richer and the poor were being marginalised faster than ever before. Widely read as an effort to forestall likely May Day demonstrations in 2008, the government was moved to give its citizens five thousand patacas each, one might disingenuously claim, to make tangible the idea that the new prosperity was being shared. With these circumstances in mind, one may match Wong Man Fai's island metaphor with Debby Vai Keng Sou's image of a house being offered to the citizen:

\section{a big house}

I am offered

a big house

the keys to the house

he keeps

I'm just a little woman

need a home

in this smalltown of mine

miraculously expanding by the minute

less and less space to breathe

a big garden in front

roses greeting me in pink and red

to grow 
to pick

to smell

priceless furniture

mahogany

style

cool

a balcony to the sea

good view for a change

from there

to watch the world

to be watched

o, vanity

I am promised five thousand kisses too

dry on the cheeks

no love

May, 2008

In Sou's poem, the "five thousand kisses" are easily recognised. Highlighted here is the contradiction inherent in Macao's style of progress- more territory, less space to breathe. The new opulence is somehow vain and loveless; really it's all about what one might call a local style of voyeurism - a "see and be seen" ethos.

The subject knows she is hailed; or in Stuart Hall's "articulation" theory we might say: here is a subject who recognises herself as discovered by an ideological apparatus. She contends with - she contests - her interpellation by reading more into the government's gesture than the innocent sharing of wealth it is intended to demonstrate. An ironic effect is achieved by attributing human affect in the form of a putative love to what's offered. But no - there isn't love; the cheeks are dry - the gesture was rote, was pragmatic; as Portuguese kisses might more generally seem to the casual Chinese observer.

Macao's sub-national identity entails some forms of identification unique to Macao. Things Macanese - like the patois (patua), like certain examples of Macanese cuisine - have the advantage, for the poet wishing to give local flavour, of being unmistakably of a place. In Macao's case, being a territory with integral borders, laws, currency and telecommunications, some of the official aspects of identity usually thought national apply. This too has its poetic uses. Consider Hilda Tam's 
poem "tossing the old one pataca" (the pataca being uniquely the unit of currency in Macao).

\section{tossing the old one pataca}

between sense and nonsense pots and pans in the brain that's the speech of the self

because words won't mean I pick up a coin from the desk two delicate pictures

one I call yes

and the other side no

so double the meanings

tire the mind

the lion nods -

that's the signal

air flows

while the coin spins in it

it's fate

falls into the palm

why are there

just two answers?

There's mystery added by the fact that it's the "old” pataca, not the coin currently in circulation. But there's nothing else in the poem to link it with Macao; it's this one central image - highly specified - that places this meditation on what must be admitted a very Macao conflation of themes - luck, choice, meaning, decision.

The gambling theme is one that has increasingly been given Macao characteristics in recent poetry. In the "blind" section of Pierre 'Tai Pi' Wong's poem "midday images", the reader is shown how everyone's field of vision is diminished by focus on the object of luck and the moment of winning or losing. 


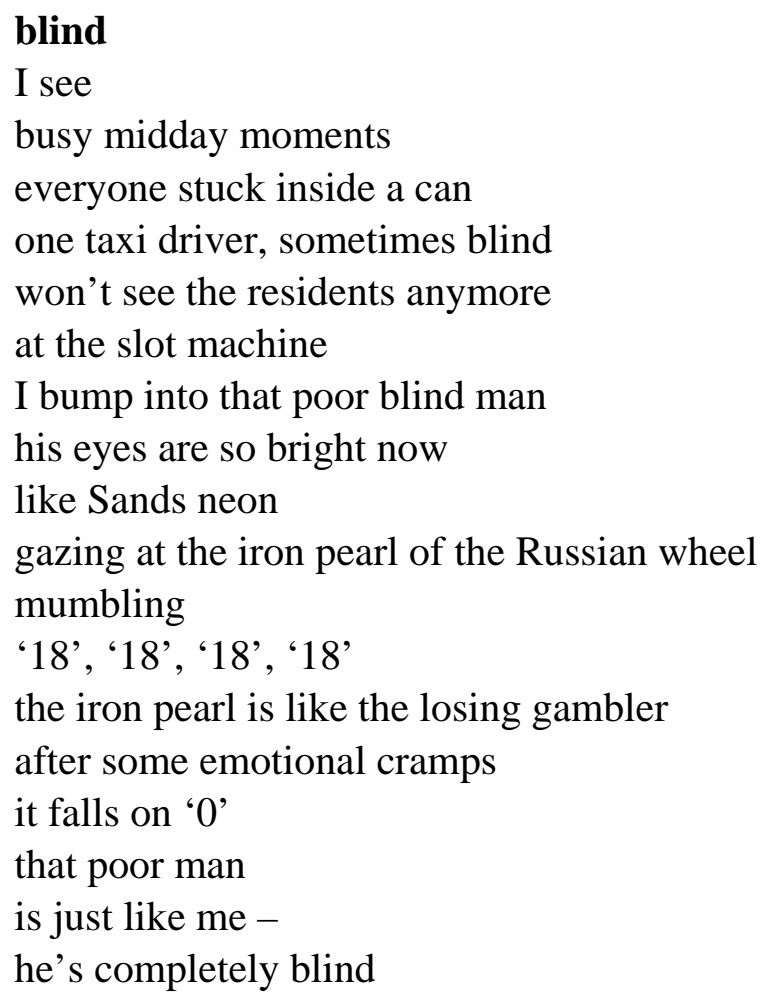

AV \& KK (270-1)

Blindness manifests in several related ways in Wong's poem. The taxi driver is a danger to the pedestrian residents because he sometimes won't see them crossing the road, and then there's a real blind man in the poem (with blazing eyes to remind us of Dylan Thomas' famous villanelle). The brightness of the blind man's eyes is likened to that of Sands neon (i.e. the neon signs of the Sands Casino, opened in 2003, first of the new generation of casinos). This brings us by association to the object of the gambler's gaze, which is the roulette ball. We hear the gambler's prayerful incantation, his mumbled wish that the ball land on his number, which of course it doesn't. All of this provides an unexpected analogy with the poem's persona. We learn that s/he too is blind and that this surprise has the disturbing effect of suggesting that everything we've gleaned so far through the poem (images, associations, analogies) has been unreliable. So that we the readers are literally in the position of the blind being led by the blind. Implied here, I think is that there is no stable point of view available from which the city or anything in it might be viewed. Nor is this merely postmodern effect for its own sake. It's a pattern of metonymic shift - glissement - driving through this poem that prevents the reader's eye from resting on any particular image or any certain analogy. The effect overall is to simulate the infinitely distracted experience of the gambler - of the one obsessed with the win/lose evanescence of luck in the vanishing here and now. In case the reader might be tempted to look for hopeful signs, in the last section of the poem, “darkness”, the reader's offered this conclusion: 


\title{
darkness
}

\author{
darkness \\ spreading after noon \\ we've been searching \\ hoping to leave the lost \\ then you will discover \\ we are together \\ completely blind - \\ this century's horrible disease
}

(271)

Here we read some of the ethical questions characteristic of the Macao casino poem and its overarching interest in the idea of an economy premised on the voluntary taxation of those who come from far flung places because they are addicted to chance.

\section{Whores, Beggars, Gamblers,}

Concomitant with the gambling interest (remaining with the theme of luck/chance), a fascination with beggars is widespread among Macao poets of recent time, for instance in this collaborative poem by Hilda Tam and Sidney Ung.

\section{pedestrian overpass, Rua do Campo}

high over the street of bosses passing horns sounding from under man half naked and a little limbless keeps kowtowing bom bom the forehead hits the pavement which is his platform stage over the street bom bom

for the punters a coin or a note drops they give or they won't he's still a professional nothing can break his calm 


\author{
this lying around \\ is never restful \\ bitter hands around the bowl \\ hard work got him there \\ lunch time \\ break for the chicken rice box \\ just like the rest of us \\ he eats! \\ and when he goes \\ back to work \\ bom bom \\ you too can be his boss \\ just one pataca \\ or a crumpled ten's \\ all it takes \\ the same coin \\ always comes back \\ attach it to a string \\ see how long \\ a man can kowtow
}

(328-9)

As in Freud's "fort/da" game we see in outline the symptoms of a repetition compulsion. And this psychological dimension is mapped over the socioeconomic conditions, simplified to the form of Hegelian master/slave relations. There are various questions we might ask about roles and reversals here. For instance - who is the worker and who is the workless in this picture? Who is deserving, who is undeserving? And who is kowtowing to whom? Or to what? One of the ironic fantasies the beggar's figure inspires is that - having come still in the rat race chaos $-\mathrm{s} /$ he might be the one ahead of the game. In this sense the beggar is a figure of reversal.

Let's turn now to an older example of the beggar portayed, in part of a poem from one of the key Portuguese voices in Macao today, that of Carlos Marreiros. From a 1980 poem, “An Old Umbrella”:

wire's bony frame

hidden by rag

a bit of skin

wind's arms

belly is nothing 
on the hill

of last night's rubbish

empty hands of the beggar's carcass

surrendered to its own condition

failure, inferior, unjust

after all the attempts

impossible yet

not yet thirty

but centuries past

the point where everything begins

and everything ends

the condensation of all and of nothing, and all at once

where there is no history

neither does age make sense

LH \& KK(113-4)

I think the beggar is a figure of fascination for Macao poets today because s/he embodies certain contradictions inherent in Macao's new found gambling oriented wealth. The beggar can be seen as the negative figure of luck, the character cast on the street through bad luck - the very type of the aphorism "there but for the grace of God, go I.” And the beggar is suggestive of alms and so of religious obligation. In Macao the question will always be - which religion (?) - and so I think we can ask - which obligations (?). The beggar is also a figure of distrust - (Is $\mathrm{s}$ /he genuine? Is s/he part of an organised scam?). So this character is victim of the economy but also somehow an image of corruption or at least of doubt, of dubious morals. The point is that the beggar is a type/figure/character who begs questions about the identity of Macao and its inhabitants more generally. The figure of the beggar embodies questions as to whose place it is, as to who is deserving and who is not, questions as to who is the real thief - of time, of money, of identity.

The gambling oriented society producers all kinds of losers. In a general sense it's been possible in the past to see the whole of the Mainland's population somewhat in the light of Hans Christian Andersen's little match girl - folk sadly excluded from the warmth and the fun of a capitalist economy. An example of that no longer viable - thinking is in José Silveira Machado’s “The Rickshaw Man”.

he came

from the other side of the river

in the tide's flow

held in waters of hope

night without stars

empty pockets 


culture Unbou
pedalling the hungry lanes
sipping at bowls of rain
sleeping under the cold awning
gone in the wind's wings
lives alone
the rickshaw man
sits in night's shadow
neither would gods comfort him
rot in the heart
of the life without hope
nothing in pockets
with holes
the rickshaw man
lives alone

LH \& KK(24)

It would probably be fair to say that most of Macao’s population came from the "other side of the river" at some stage in the last century. Since the opening up of the eighties it has become progressively more difficult to look pityingly en masse at the population of China. Perhaps a more nuanced view of the state of play with winners and losers is presented in Hilda Tam’s "my whore at Rua de Cantão”.

I saw a whore

in an ad:

red hair

blue eyes

big tits

fat bum

I gulped

I felt in my pocket

I went into the sauna

and there she stood:

red hair

blue eyes

big tits

fat bum 
ashamed

I stepped back

back to gaze at my whore

in the ad

The winner's prize may be easier to stomach in prospect and in virtual form than in flesh and blood.

\section{Depicting City Space}

Consciousness of place in contemporary Macao poetry appears to be dominated by two kinds of space; I will gloss these here as "Macao space” and "anywhere space”. In his 1995 monograph Non-places: An Introduction to an Anthropology of Supermodernity, Marc Augé describes three "figures of excess...employed to characterize the situation of supermodernity". These three figures are "overabundance of events, spatial overabundance, the individualization of references" (4041). Augé writes of an "excess of space...correlative with the shrinking of the planet”:

with the distancing from ourselves embodied in the feats of the astronauts and the endless circling of our satellites. In a sense, our first steps in outer space reduce our own space to an infinitesimal point, of which satellite photographs appropriately give us the exact measure. But at the same time, the world is becoming more open to us. We are in an era characterised by changes of scale - of course in the context of space exploration, but also on earth: rapid means of transport have brought any capital within a few hours' travel of any other. And in the privacy of our own homes, finally, images of all sorts, relayed by satellites and caught by the aerials that bristle on the roofs of our remotest hamlets, can give us instant, sometimes simultaneous vision of an event taking place on the other side of the planet. (31)

Of the world's computer screens, Augé writes:

We can say of these universes, which are themselves broadly fictional, that they are essentially universes of recognition. The property of symbolic universes is that they constitute a means of recognition, rather than knowledge, for those who have inherited them: closed universes where everything is a sign; collections of codes to which only some hold the key but whose existence everyone accepts; totalities which are partially fictional but effective; cosmologies one might think had been invented for the benefit of ethnologists. (33)

Cosmopolitanism, since ancient times, has been the privilege of an elite capable of exercising the knowledges and recognitions required to transcend the ground on which a subject stood as particularly of a place and bound to place. It's in such a sense Macao's poetry today may be regarded as broadly cosmopolitan - i.e. constituted in overlapping universes of recognition, to which the poets in question and their good readers, hold the appropriate keys. But today's cosmopolitan elite lacks the defined knowledge and identifications of ages past. 
On the macro scale we can read Macao as an open door through which goods, capital, humans and their imaginary references all circulate, sometimes at a dizzying pace. A cinematic sense of the place (discussed a little below) then does perhaps convey an idea of (what Augé names spatial overabundance). Late noughties advertising for Macao as a tourist destination (as for instance shown non-stop on the jetfoil from Hong Kong) reveals the dot on the map as making available to its citizens and visitors every conceivable kind of space and concomitant activity windsurfing, tower viewing, bungee jumping, heritage walks, leafing through ancient tomes in a library, dining in every style imaginable and of course placing bets on the gaming tables. On the ground though, during the boom years now passing, public transport had increasingly become an undesirable way to get anywhere. With no particular brakes on the acquisition of private vehicles by the wealthy citizenry, at peak hours a great proportion of the cars on Macao's roads are there because their drivers are simply trying to park; leading to the maxim that to go anywhere in Macao one must first go everywhere.

For Augé, important characteristics of non-place include "an experience without real historical precedent - of solitary individuality combined with nonhuman mediation (all it takes is a notice or a screen) between the individual and public authority" (117-118).

\begin{abstract}
Clearly the word "non-place" designates two complimentary but distinct realities: spaces formed in relation to certain ends (transport, transit, commerce, leisure), and the relations that individuals have with these spaces. Although the two sets of relations overlap to a large extent, and in any case officially (individuals travel, make purchases, relax), they are still not confused with one another; for non-places mediate a whole mass of relations, with the self and with others, which are only indirectly connected with their purposes. As anthropological places create the organically social, so non-places create solitary contractuality. (94)
\end{abstract}

It's interesting to think of "solitary contractuality" in terms of a slot machine culture: the slow lonely process of making a fortune or losing the lot. And yet the crowdedness of spaces in Macao (in China/East Asia more generally) belies the sparsity and the inhuman aspect Augé associates with "non-place":

\begin{abstract}
But the real non-places of supermodernity-the ones we inhabit when we are driving down the motorway, wandering through the supermarket or sitting in an airport lounge waiting for the next flight to London or Marseille-have the peculiarity that they are defined partly by the words and texts they offer us: their "instructions for use", which may be prescriptive ("Take right-hand lane”), prohibitive ("No smoking”) or informative (“you are now entering the Beaujolais region”). (96)
\end{abstract}

Macao has such signage, to be sure, and yet the average citizen's (or vistor's) experience of it would be brief. In Macao - the particular paradox with regard to the signing of non-place space - is that what makes it particular is the fact of it being exoticized as incomprehensible. The street and shop signs compulsory in Portuguese cannot be read at all by the vast majority of the population; nor can Chinese tourists read the Portuguese; nor in general can western tourists read the Chinese or the Portuguese signage. Of course a Portuguese name, written in the 
Roman alphabet, will serve for a name in English or in any other European language. But try telling such a name to a Macao taxi driver and - good luck. The main street of Macao is, to the population at large, San Ma Lo. Ask anyone about Avenida da Almeida da Ribeiro (the Portuguese name) and you'll get a blank stare. The sign in Portuguese is something people simply don't see (the way I don't see the Chinese characters on the keyboard on which I'm typing this - because they are simply not relevant).

To return then to a distinction between "Macao space” and "anywhere space”. Macao space is uniquely of an historical moment and place, something culturally positioned; in anywhere space (e.g. inside of a casino or an airport) subjects are hailed by consumption-oriented reifications of putative universal value. In the terms Umberto Eco elaborates in The Role of the Reader, we recognize in anywhere space a "closed text", i.e. a text in which the addressee is not invited to participate actively, but is rather offered a pre-determined role, open neither to interpretation nor negotiation. Macao space, being particular, is contingent. Having a history, it can have a future. The contemporary Macao poetry typically values Macao space and sees it as under threat from the "non-negotiable” space of culture that could be anywhere.

In Loi Chi Pang's poem, "to Coloane”, ${ }^{3}$ we get a picture of anywhere space being added to Macao:

\section{little city too cramped}

so cramped that there is only space left for muttering

the many roads not taken knit into a helpless net

skims from my eyes

under the net there is such a stunning hope

a naming for all kinds of new things

simply

a word

“cold”

the autumn of September here is a book of sorrow more than sadness so sad that the egret can't stand any longer under the mangroves holding up an oilpaper umbrella to Coloane

I can't see rain

but only

ashes and stones of the cement trucks

flying past

and

the Cotai Strip

still under construction

HT \& KK (290) 
Here, witnessing the process of "reclamation" shows us that liminal space green space in this case - cannot become a part of the known place. The egret will be deprived of its mangrove; instead the "new things" are worthy only of the word "cold". This is anywhere space is the making; and it's made of ashes and cement, of anything.

In Erik Lo Yiu Tung's poem "the city starts to flee with the speed of the stars", we indulge the fantasy of the city escaping a violence of growth even dreams can't conceal.

\section{the city starts to flee with the speed of the stars}

grow up rapidly, the city starts

to flee with the speed of the stars

used to chase after each other in the park when young

one year the hand of the clock was sprained

even dreaming can't conceal

the violence of growth

after dark the street becomes the future trenches of the children they have been asking lots of questions that adults can't answer when I was young, mother fooled me and said those were just accidents

perhaps there are too many accidents beneath the sky, for example:

on the street in June or July, we might have

met behind the police tape

watching the city continually flee with the speed of the stars

it turns out that there are still lots of unanswerable doubts

within the distance that can't be asked

I have long been used to that

\section{EL \& KK (324)}

Where is the poetry in this? On which side of the police tape? Clearly accidents are suspicious; some transgression is indicated. Doubts are unanswerable, space and time as we knew them can no longer be relied on - the clock is sprained, the distance cannot be asked. In these circumstances the idea of the future is reduced to trench warfare.

In Xi Lan's “it's only in death we're not foreigners” we get a skewed picture of the poet's place:

the view through the mirror

is the reflection of contorted reality

I suddenly lost all hopes, but am joyful 
I lie below the Ruins of St Paul - they're under construction drinking a beer once cold, following the whole city working hard at being dispirited breathing in the air breathed out by others as I understand it, poets have always tried to live well in other people's lives

$$
\text { JL \& KK (379) }
$$

In the touristic city the ruins are under construction. Life is close. We breathe in the air others have breathed. We see that even poetry is a compromised activity; it's essentially parasitic. Poets try to live well in others' lives. Tam Chon Ieng's “a game”, by contrast shows us poetry as a kind of resistance to the house becoming unknown:

the world can almost stop, the rotten sound of the bell hasn't submitted to poems poets stand one by one next to each other thinking with their eyes covered, they finish the game in the midst of the singers

too many people enter, more and more stones in the house can no longer be known

HT \& KK (386)

\section{Cinematic Un/consciousness of Space}

What kind of a space is a city? Is the city in particular? Is any city anywhere? What relationship obtains between the city in particular and any city anywhere? I think there are useful terms of analogy with the relationship we can theorise between nation in general and a nation in particular. Benedict Anderson's second paradox of the national is that nations are particular instances of identity of which all persons are - at least notionally - possessed (5). That is to say, nation is a kind of universal difference: everyone's nationality is not the same as someone else's. Along these lines, a key paradox of "anthem quality" (the soul stirring evocation of national sentiment felt by those who stand for their national anthem) is a uniformity of differences. Every member of the series "nation" must have a national anthem; as a consequence, though anthems are notionally intended to express the differences between nations, reflection reveals that they serve also to illustrate the consistency of national investments across international borders. In other words, although people generally feel that expressions of devotion to flag or soil or anthem or any other abstraction of national homeland are particular, and suggest distinction from the devotions of others to other places, in fact dedication to nations in particular is - as evidenced by the machinery-in-common - the shared worldwide "spiritual" commitment of the modern citizen. In this sense we may think of national devotion as essentially devotion to the notion of nation. 
Devotion to a city (for instance the artist's or writer's commitment to the representation of his or her city) has a number of similarities with national devotion; and yet it is a less abstract devotion in that the city's citizens are - relative to those of the nation - more likely to have met each other. They are also likely to have more in common: they breathe the same air, experience the same weather. So the connection is more natural, less manufactured.

In her 1995 volume The Culture of Cities, Sharon Zukin writes, "for several hundred years, visual representations of cities have "sold" urban growth... Images, from early maps to picture postcards, have not simply reflected real city spaces; instead, they have been imaginative reconstructions-from specific points of view —of a city's monumentality" (16). Zukin tells us, "Cities impose visual coherence in many ways: by using zoning to impose design criteria for office buildings, by making memory visible in historic districts, by interpreting the assimilation of ethnic groups in street festivals, by building walls to contain fear" (77).

From the point of view of the current investigation, the point needing made is that a city's poetry does not represent some kind of objective or independent witness of place. However obscure or difficult it may seem, poetry is not above or outside of the cultural processes by which places and peoples represent or symbolize themselves; rather it is - as other forms of culture are - bound by what we might think of as a culturally produced aura of the place, for which purpose the whole is always greater than the sum of its parts. So poetry and the points of view it expresses are bound up with more general attitudes and opinions of places, with the everyday loyalties and doubts people have for the places they identify as theirs. And the poetry of a place, produced as it mainly is by a cultural elite, is naturally a vehicle for a critique, both of the culture in general, and of those specific representations - especially the official (for instance the touristic) representations- which impact on "the place in mind" experienced by inhabitants, by visitors and by outside observers.

In Tourism and the Branded City: film and identity on the Pacific Rim Stephanie Donald works through three case studies (Shanghai, Hong Kong, Sydney) to look at inter alia how "the tie-in between enhanced film locations and national tourism campaigns offers a perfect commercial and creative synergy between the digital media, the film industry and the tourism agencies” (2). Donald writes that it is:

no secret that the global narratives of cinematic affect and urban resonance are rooted in the pre-eminence of American and European cities. This is due in part to the academic and popular publishing power in those regions and also, need it be said, the phenomenal success of American film export over the past century. Everyone who sees films knows, or thinks they do, what a US city looks like. New York, San Francisco, Chicago and LA are embedded in cinematic consciousness, thanks to the many versions of those cities that populate the Hollywood screen. Even specific locations (the easterly view over the Hudson River, the running path by the basketball courts in Central Park) are recognizable to viewers who have never set foot in 
the United States. Europe also has its cinematic cities: Berlin, London, Paris and Rome. (4)

Embeddedness of cinematic consciousness (and perhaps more importantly of cinematic unconsciousness) clearly prevails in the case of Macao, in a poetry that is written with cinematic ways of seeing space in mind. Take for example Siu Hey’s poem “developing a port - repertoire”:

prelude, <xylophone concerto $>$

please switch off mobile phones

for the purposes of historical reflection

messages can't be sent four hundred years back

the church is a light-purple ticket

gets you into Lang Bai Ao the moment the storm stopped

iron strikes against flesh composing a drum rhythm

but the melody is sour

now

you command I order

cruel applause

and weeping

\section{second, <majestic march $>$}

drums and cannons

mate under the statue

of Governor Ferreira do Amaral

waving to you

recruiting you to join the hero who destroyed opium

the lotus stone is for cutting open the belly

so it's redder than Christmas flowers

smiling need not entail frivolity

blood is flowing in the east

heroes’ hearts beat slowly

The overt musical structure of the piece belies the filmic - it could almost be read as scenario (plus commentary) for a commercial-length film montage. Yi Ling's 1989 poem, "filming in the residential district" avows the space of the poem as cinematic: 


\section{filming in the residential district}

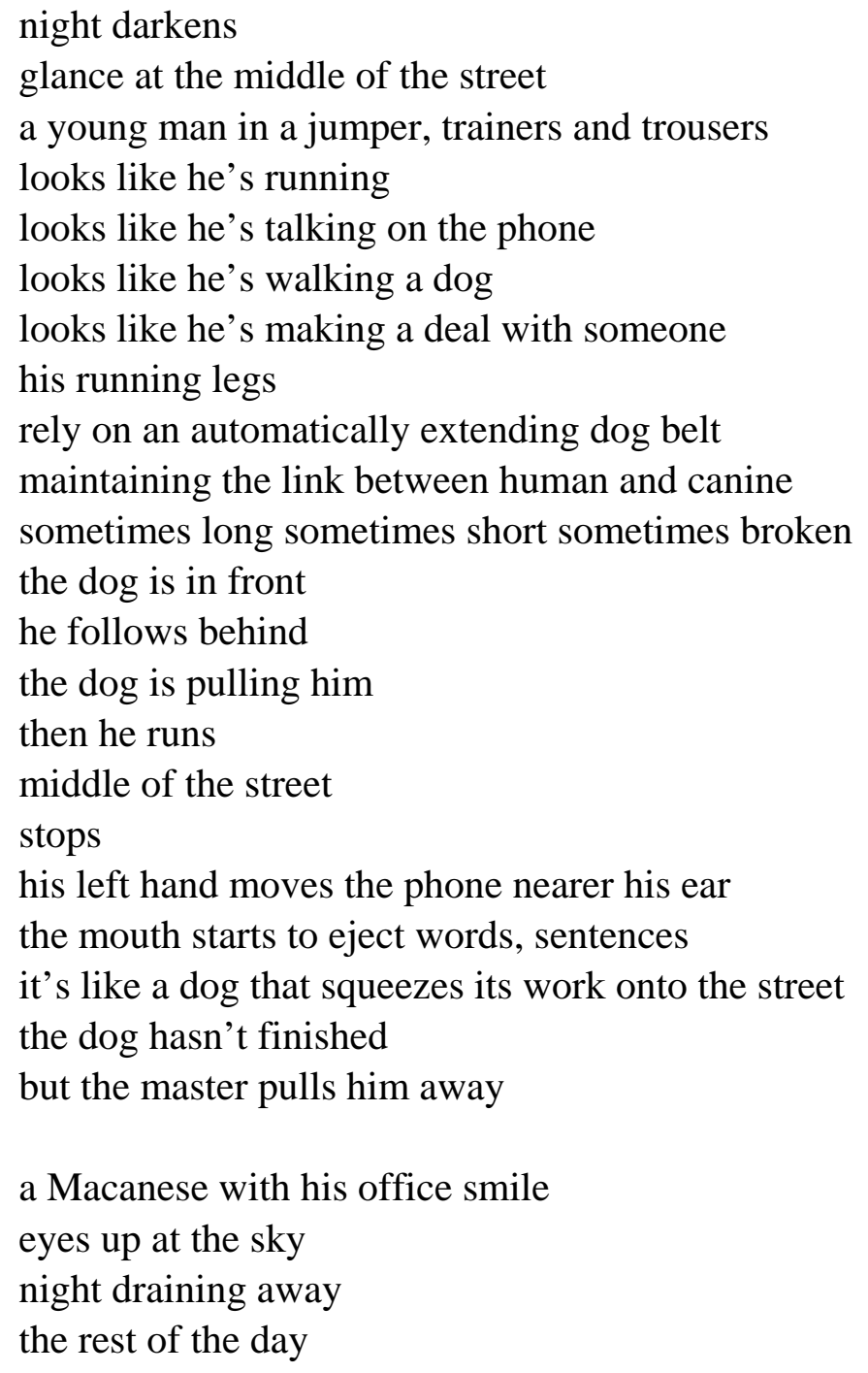

And in Lou Kit Wa's “inspirations of the chicken”, we likewise witness directed space.

of course, having a pair of wings

rather than a pill or a dance floor

makes the ears and eyes wild

angers the hair

and then

you forget your identity 


Culture Unbound
journal of Current Cuttural Res
your parents
guilt
forget about its iron cage
their bodies get close to each other
wiggling
falling to the ground
waiting for dark night to enter
directing a film's plot
choking the city with sobs

AV \& KK (301)

Who's directing and who's directed here would be somewhat more difficult to establish. As in Lou's poem, one sometimes finds a surreal cartoon quality - an oneiric city of impossible transformations is conjured, as in Erik Lo Yiu Tung's "sleepwalking":

your world slims down, flowing along the river outside the window little birds also fly away, you said as if once you spread your hands you could touch the edge of the sea

the bottle has been collecting the rain recording restlessly just like a typewriter hey! you naughty kid you throw the bottle on purpose towards the edge of the sea. you said to step across time, we even step onto our own heads!

you're a wolf, also a sheep for example, if a hunter suddenly had to shoot you down you would flee right across the swamp, the river, go through the forest flee to the path that leads to the life of sorrow finding the only entrance

hey! do you really need to pick the poison worm seed from the dream scheme? that pair of devilish hands which direct fate will soon let eyes drop into the ocean of lashes you haven't got over the sleepwalking it doesn't connect at all

EL \& KK (323)

This cinematic un/consciousness of space is, in Macao's case, despite the fact that Macao space - unlike that of New York or Paris or Rome or Hong Kong has 
not been the object of a long tradition in film; nor would its landmarks be easily recognized by an international film-viewing audience. Macao's space is however cinegenic. The fact that it has not much been depicted in actual cinema provides poets with both opportunity and responsibility. The place is changing so quickly, there is danger at every moment that a particular ambiance will be irretrievably lost.

Stephanie Donald writes, "there is a local sense of belonging that is particular to Hong Kong and which makes narrating the city-as-brand a delicate task. When this narrative task is tested against the work of filmmakers, arguably the strongest voices in Hong Kong's cultural worlds, it emerges that the competing patriotisms are not invariably commensurable” (5). The patriotisms to which Donald refers are, in Macao and Hong Kong's cases, embedded in similar problematics: loyalty to the colonial past or the national future; to the East, to the West; to the local or the larger identity. A key difference is that in Macao's case, filmmakers could not be argued to be strong voices in Macao's cultural worlds. Theirs would be fledgling voices in Macao; there simply aren't enough of them. Instead, poets, architects, visual artists, designers, musicians - these are Macao's strong voices in culture today. ${ }^{4}$ Perhaps it's the fact that in relative terms poetry need not be so time consuming activity that has allowed this perruque 5 to be the favoured form of expression of so many Macao intellectuals. In a sense hitherto not much recognized, I think poetry has served as witnessing vehicle of choice because, in recent decades, it has had the critical mass of a tradition in Macao. Macao's poets are free to play with what is poetic in the cinematic view of their cinegenic space and without needing to actually make films. And yet the Hong Kong cinematic eye is well at home in Macao and plays a defining role in the way Macao space is perceived. The strength of local talent in other areas suggests Macao's is a cinema waiting to happen (one likely to be influenced by the city's part-time poets when it does); and at the same time it needs to be conceded that Macao space is seen by its imaginative citizens through a lens of Hong Kong, Hollywood, Mainland and other cinemas.

\section{Macao's Symbolic Place - a Sleepwalker's Macao}

Seeing one's own place with other eyes (detached observation) is a characteristically cosmopolitan and modernist malaise, lot of the flâneur for instance. Macao is a pedestrian-scale place and, because of what we now call "heritage”, peninsula Macao is one of the world's great city spaces for walking. Walking in Macao's Inner Harbour streets is making one's way through decay, through remnants of past culture. In fact one may read miniature Macao as the paradigm walking city; it's too small to see any other way. To walk is to observe, to understand and to leave traces of all of these processes. Walking is a kind of writing. Footsteps for de Certeau are like Chinese characters drawn with a finger on a hand: "they are 
myriad but do not compose a series. They cannot be counted because each unit has a qualitative character: a style of tactile apprehension and of kinesthetic appropriation. Their swarming mass is an innumerable collection of singularities. Their intertwined paths give their shape to spaces" (97). For de Certeau, the "long poem of walking manipulates spatial organizations no matter how panoptic they may be: it is neither foreign to them nor in conformity with them” (101). Noughties Macao does have its panoptic point - the tower and its view and its bungeejumping spectacularism; things captured on film and offered the tourist.

The cinematic impression a city makes melds seamlessly into another (and closely related) mise-en-scène: that of the dreamer. In Lok Ka I's "homesick on a soundless night”, the question of displacement stands ironically at odds with a ersonal sense of placelessness.

where is my home?

heaven knows

homesick thoughts of missing

no reason for a cheerful face

no footnote for a broken heart

on a swing

a dream of the future sways

'can't bear to climb high to look beyond

my hometown far away

I shed tears for bygone years

why does the pain remain?...'

on a bustling street

who wants to be a lonely walker?

I keep my own counsel

see afar

not going home, just passing

life is tedious

seeking reasons to set roots

clouds are stirring in the air

it's difficult to breathe

got to find an excuse

to smash a glass plate

a good many times

order a cappuccino

drop in a cube of sugar 
together with the bubbles I swallow all that was clear awake after

the coffee reminds me of the moon of my town drinking alone on a moonlit night

DS, JH \& K (368)

On a bustling street/who wants to be a lonely walker? "To walk is to lack a place”, de Certeau tells us. In the city of pleasure and potent illusions (i.e. those on which a gambling industry depends) the oneiric and the ambulatory can read as views through the one miasma. For de Certeau - "the similarity between 'discourse' and dreams has to do with their use of the same 'stylistic procedures'; it therefore includes pedestrian practices as well” (102). In the city, as in the dream, things needn't make sense. The connection is already made in the last line of Erik Lo Yiu Tung's “sleepwalking”: “it doesn't connect at all” (323). But things contiguous with no appearance of connection are things which require interpretation; as for the dream, so for the city.

Dreams are a major preoccupation in Macao poetry today. The idea of Macao the city or territory - as a dreaming entity or a sentience in itself capable of dreams is the subject of the experiment in Fernando Sales Lopes' poem "Macao":

\section{Macao}

You're open to the sea

inside

you want to escape

from your fate

Rough toss

and you reach

to conquer

the body

seized

by the earth

You dream...

You dream you are

what you were by chance

But your destiny

is written

in the smoke 
that protects men

and appeases gods

The grand mother

holds

your body

And the soul

returns to her

\section{LH \& KK (139)}

Here Macao, the sleepy outpost, is personified as a character wishing, but unable, to escape fate. This sleepy Macao image - so hard to sustain today - is an important reminder of what Macao has meant - especially to the Portuguese - for most of its modernity. Today's Macao resembles some heretofore unknown cross between casino, building site, world heritage antique and a place where some hapless folk are just trying to get on with their lives. It's a place sleep cannot be relied on. And when sleep won't come ? Terence Hun (Ling Gu) gives us the picture:

\section{insomnia}

thoughts

are

gangs of wolves

one gang after another

the field belongs to them

the waves in the grass belong to them

what you have is

only their howling

your breath has nothing to do

with wind through the grass or beat of the heart

they are having a race in any direction

if you think of

a starting point and a destination

all the wolves circling

breathing, motionless

mouths opened

biting each other

your life

is like this 
Casinos, luck, chance; beggars and gamblers and prostitutes; the water and what lives in it, passes through it; likewise the air; development and reclamation; border business, dreams, poetry, art - contemporary Macao poetry negotiates a range of related themes and images, as sampled above. Investment in the intercultural and its difficulties and possibilities provides a consistent backdrop for the development of these themes.

Local poetry has had an important investment in understanding Macao's symbolic place - between east and west - and in understanding the nature of encounters across cultures here, likewise in accounting for intercultural misunderstandings. These interests are important also in the official culture (touristic and otherwise), and in contemporary Macao poetry we may detect cynicism, critique, annoyance with the official line. Take for instance, Eric Chau's poem "the silent Macao”, footnoted with the author's "ps. After Macao's successful inclusion on the world heritage listing, the

TV advertisements continuously repeated the slogan, 'a world of difference, the difference is Macau'. It became the voiceover of my nightmare at that time." Chau links this new official image with the handover. "A bitter fruit was swallowed for four hundred years", we're told, and now:

a lie that's been spoken a hundred times - truth

(a world of difference, the difference is Macau)

why does the same phrase have to be repeated a hundred times?

a truth repeated a thousand times adds a bit more than the truth just that little bit of absurdity

(a world of difference, the difference is Macau)

why does the same slogan have to be repeated a thousand times?

I'm silent

And why? On paper one may be struck by the apparent disingenuousness of the voluble protester claiming to be silent. However, what's written may not be heard and in the case of poetry perhaps it is not unusual for loud claims in ink to go unheeded. In this case, Chau's persona is silent because s/he doesn't:

...know what to say

once hurt now I can only think of the scar, an ignorant violation

hegemony is not the creature of sin or desire swept along by the postcolonial

insensitively thinking of the past calamity

but saying that it's for cultural exchange not knowing if there is such a thing 
The critique is offered in local and international terms; what's revealed is a cheapening of culture borne of the servitude expressed in the compulsory smile the smile that is itself a kind of trickery, encouraging the gambler to think of himself as a winner.

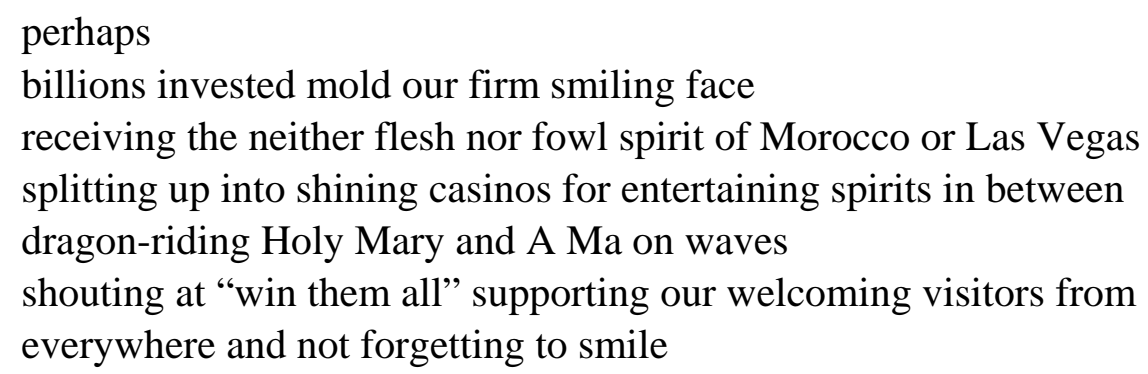

And so silence here is about the fact of being deprived of a voice; the theoretical underpinnings are unusually well articulated.

culture somebody sees it thinks that it's a business someone feels a thorn

in the heart letting the graceful heritage be restored

our confidence is fake but we have swallowed something bitter that was not

easy

I'm speechless I'm silent I don't have a standpoint

\section{I laugh}

but I'm not happy

(a world of difference, the difference is Macau)

(a world of difference, the difference is Macau)

AV \& KK (239)

Baudrillard writes, "The irony of the facts, in their wretched reality, is precisely that they are only what they are” $(1996,98)$. It's along these lines Chau captures a casino mesmerism, a circular logic and enigmatic logic - of tautology - that keeps the wheels of the gambling tourism economy greased.

\section{The City Itself}

The "city" is itself an important focus for poetry being written all over the world today and has been for more than a century. While Macao is in various ways a particular place, there are other senses in which it could be any city - any place in south China, in East Asia, in the world. Macao itself should be regarded as a work enduring (in Brechtian terms) because it is unfinished. "How long do works last?" Brecht ${ }^{6}$ asks in one of his later poems. His answer? "As long as they are not completed. Since as long as they demand effort they do not decay” (193). The 
work in process supposes a range of futures; imagining a future provides a vantage from which present conditions may be viewed. While this straightforward aesthetic provides a formula that could be notionally applied to any city, such a view seems particularly apt given both the extraordinary pace of change in posthandover Macao, and the present bubble-bursting effect of the 2008 "financial tsunami". To the extent that poetry partakes of witness of the unknowable potential of a place, we come close here to Shelley's claim about the poets being unacknowledged legislators. Through their engagement with dreams we apprehend the Macao poets as hierophants of inspiration for their city.

How are city and poets - the space of the city and the "mindspace" of the poem - connected or disconnected? How might they meet or not? One thinks of Plato's expulsion of the poets in Book Nine of the Republic; their banishment as undesirables from the ideal city state on which Socrates expands so volubly. It was with close reference to Plato's attitude to and expulsion of the poets that W.H. Auden wrote in his (1962) essay "The Poet and the City", of a fundamental disaffinity between poetic methods and goals and what he saw as the nature and the needs of the city.
The whole aim of the poet, or any other kind of artist, is to produce something which is complete and will endure without change. A poetic city would always contain the same number of inhabitants doing exactly the same jobs forever... A society which was really like a good poem, embodying the aesthetic virtues of beaty, order, econ- omy and subordination of detail to the whole, would be a nightmare of horror for, given the historical reality of actual men, such a society could only come into being through selective breeding, extermination of the physically and mentally unfit, abso- lute obedience to its Director, and a large slave class kept out of sight in cellars... Vice versa, a poem which was really like a political democracy - examples, unfor- tunately exist - would be formless, windy, banal and utterly boring. (in Scully, 179)

Playful hyperbolics aside, I think the conception of what a good poem could be has moved on somewhat since Auden's time. The multi-tasking - the "political democracy" (what Bakhtin would call the "multi-accentual”) - is common in poetry around the world today and is well evidenced in contemporary Macao poetry. We could describe Auden's position above as classically modernist, at least radically pre-postmodern. The irony is that his description of the ideal poem is actually not a bad description of the city from which Plato was expelling the poets changeless because perfected, the opposite of Brecht's conception. In fact I think poetry today is much more like the cities in which it is practised than it is like either Plato's or Auden's conceptions.

The identity, the self-image, the reflexive consciousness of the poet-as-dweller in the particular place we call a city - these are key factors shaping modernist and postmodernist poetry, its thematic/affective range and its ontological investments. Conversely, the poetic image - like the cinematic - has been a formative influence in our contemporary conception of what city space is, of how humans can or can't handle it. The poetic image of the city shapes a conception of how such spaces 
conform with our utopic or dystopic views of humanity as a species capable of thoughtful dwelling; able to get it wrong, able to make it better.

Poetry of a place is important for making us look again and not merely take for granted the objects and the activities going on around us. The criterion is definitive in the sense that the poem which does not make us look again is not really worth attending to. There's reflexive potential in that process of "re-visioning" because it maximises the chances of our seeing ourselves in the mirror which the poem-of-place naturally is.

Zygmunt Bauman writes of a sense of so-called "objective” space, of physical space arising from a "phenomenological reduction of daily experience to pure quantity, during which distance is 'depopulated' and 'extemporalized'” (145). The poem anchored in the space from which it arises tells us of a place as subjective experience; it offers the reader eyes to see, a point of view from which get the sense of a location - so it offers motives for empathy and for identification.

Macao poetry proposes and it assumes an imaginative geography, in Edward Said's terms, and in it we can recognise a tension between - on the one hand universalising and orientalising tendencies, on the other hand an engagement with the here-and-now of the place as it is lived. Then is "Macao" merely an orientalist construct of the western mind? Is there a "real" Macao being misrepresented through such means? Or is it merely a case of mutual misreading - of inevitable occidentalisms and orientalisms borne of an incomprehension which has the effect of producing "the other"?

A solution to these problems is offered in the idea of poetry as practice of "place-based aesthetics", along the lines suggested by Raymond Williams' "radical particularity" - in this case the effort to claim a place through the conscious effort of producing its culture. Poetry, in this productive sense, can be a paradigm case for Williams' "structures of feeling”: in situating our knowledge of this particular poetry, we discover through analysis that things "taken to be private, idiosyncratic and even isolating" are in fact "emergent, connecting and dominant characteristics” (132). What was taken to be personal turns out to be very political, the basis on which a collective identity (for instance that of the dweller in a particular city) is unconsciously determined through views and assumptions in common, and through the common affect these imply.

Why has poetry, in particular, been an efficient vehicle, in Macao's case, for the kind of work Raymond Williams prescribes? I think in Macao we can see poetry in operation as resistance, as witness, as perruque - in short, a kind of truth telling only possible from makeshift materials - those put to a use for which they were not intended.

Taken all in all, Macao has very few poets of the kind Plato would not have expelled for subversive activity. Some Macao poets lapse into jingoism now and then; in all but a few cases this is an aberration. The general posture is thoughtful, critical and self-aware. These poets write (and they read) as if everything were 
open to question. It is often a painful duty. As Jean Paul Sartre would say, they write as if they were condemned to freedom. Perhaps the pain here is a postcolonial burden; however one considers it, Plato's Socrates would have to acknowledge that Macao's poets are leading the examined life.

Some are wiser or deeper or more biting than others, but I think we can say that there is a strong human rights agenda built into the poetry. It's not any sledgehammer politics - it's not some pointed campaign - rather it's a case of leading by example. Macao's word artists take it as a solemn duty and as a solemn kind of fun as well to criticize everything that needs criticizing in their city. And so they live out the ever-apt dictum spelled out in Auden's 1938 sonnet "Macao" - that “nothing serious can happen here” (1945, 18-19).

Christopher (Kit) Kelen is a well known Australian scholar and poet whose literary works have been widely published and broadcast since the mid seventies. The Oxford Companion to Australian Literature describes Kelen's work as "typically innovative and intellectually sharp". He is also an Associate Professor in the English Department at the University of Macau, where he has taught Literature and Creative Writing since 2000. Kelen is the editor of the on-line journal Poetry Macao and poetry editor for the monthly lifestyle/current affairs journal Macao Closer.

\section{Notes}

1 Throughout this paper, translators' names are given in initial form at the foot of the poem (or other text) where appropriate. Here is a list of the translators with their initials.

AK: Athena Kong

A: Lam: Agnes Lam

AL: Anita Leong

AV: Agnes Vong

CI: Christine Ieong

CW: Carmen Wong

DB: David Brookshaw

DS: Debby Vai Keng Sou

EL: Elisa Lai

HT: Hilda Tam

IF: Iris Fan

JH: Jacque Hoi

JL: Jenny Lao

KK: Kit Kelen

LH: Lily Han

ME: Maria Antónia N. Espadinha

SZ: Song Zijiang

Note that because much of the poetry cited in this paper originated in the anthology I Roll the Dice: Contemporary Macao Poetry [published by ASM in Macao in 2008], where only a page number is given in the in-text citation, the reader should assume that the extract is from that source. 
2 In 1887 a Luso-Chinese treaty was signed allowing Portugal's perpetual occupation and management of Macao. The Peking government, however, never ceded sovereignty over Macao to Portugal.

3 Coloane is the outermost (and larger) of Macao's two islands (the other being Taipa); Taipa and Coloane are now joined by what is called the Cotai Strip, a Vegas style casino-row featuring the Venetian (second largest building in the world), a golf course and sundry other casino resorts.

4 One notes also the passing of hats among the personae in the case of particular individuals, a 'Renaissance Macao man’ such as Carlos Marreiros being an apt example - architect, poet, designer, graphic artist, painter.

5 Michel de Certeau calls a perruque a resistance which suggests a need to imbue desire with a creative personality:

La perruque is the worker's own work disguised as work for his employer. It differs from pilfering in that nothing of value is stolen. It differs from absenteeism in that the worker is officially on the job. La perruque may be as simple a matter as a secretary's writing a love letter on 'company time' or as complex as a cabinet maker's 'borrowing' a lathe to make a piece of furniture for his living room. (1988: 25)

De Certeau's perruque diverts time 'from the factory for work that is free, creative, and precisely not directed toward profit' (25). Its pleasure is in the cunning creation of gratuitous products, the purpose of which, in signifying the worker's capabilities, is to 'confirm his solidarity with other workers or his family.' 'With the complicity of other workers... he succeeds in "putting one over" on the established order on its home ground' (26). In de Certeau's estimation it is in popular tactics that order is 'tricked by art'. The perruque is work which is foreign, homeless, by virtue of having no dwelling but time stolen from official consciousness.

6 Brecht made what we might consider an analogous investigation of city space, in the case of Berlin, in his 1920’s poems, 'Reader for City Dwellers'.

\section{References}

Anderson, Benedict. 1991. Imagined Communities. London: Verso.

Auden, W.H.. The Collected Poetry of W. H. Auden. London: Faber and Faber. 1945.

Augé, Marc (1995): non-places - introduction to an anthropology of supermodernity, Trans. John Howe. New York: Verso.

Baudrillard, Jean (1996): The Perfect Crime, Transl C. Turner. Verso: London.

Bauman, Zygmunt (1993): Postmodern Ethics, Blackwell: Oxford.

Brecht, Berthold (1976): Poems 1913-1956, Methuen. New York:

De Certeau, Michel (1988): The Practice of Everyday Life. Trans. Steven Rendall. Berkeley: University of California Press.

Donald, Stephanie H. (2007): Tourism and the Branded City: film and identity on the Pacific Rim. London: Ashgate.

Kelen, Kit and Vong, Agnes (2008) (eds): I Roll the Dice: Contemporary Macao Poetry. Macao: ASM.

Scully, James (1965) (ed.): Modern Poetics. New York: McGraw Hill.

Zukin, Sharon (1995): The Culture of Cities. Oxford: Oxford University Press. 